\title{
O CONCEITO DE ENSINO MÉDIO INTEGRADO: Um Confronto Entre Docentes Licenciados e Docentes Bacharéis
}

\author{
Sthéfany Araújo Melo ${ }^{1}$ \\ Welisson Marques ${ }^{2}$
}

\begin{abstract}
RESUMO
O Ensino Médio Integrado (EMI) ao Curso Técnico convive com múltiplas interpretações entre os próprios profissionais da educação. Este artigo é resultado de uma pesquisa que objetivou investigar, por meio de entrevistas individuais com 16 docentes efetivos, a origem dessa dessemelhança do conceito de integração de ensino, na tentativa de descobrir se o tipo de Graduação acadêmica (Licenciatura ou Bacharelado) dos docentes interfere na construção desse conceito. A base teórica deste artigo apoiou-se em Ramos (2008), Ciavatta (2005) e Araújo e Frigotto (2015). Como resultado da pesquisa identificamos que todos os 16 docentes interpretam, por um viés funcional, o conceito de integração de ensino da mesma maneira, ou seja, colocar em prática a Educação Profissional harmoniosamente às disciplinas propedêuticas, tais como Matemática, Língua Portuguesa, Geografia, Biologia, etc., de forma que os conhecimentos para a vida e para o trabalho sejam construídos de forma indivisível. Por outro lado, em um viés holístico, apenas cinco docentes acreditam que a integração deva ser fundamental não somente no momento das escolhas metodológicas para a exposição dos conteúdos, mas também nas etapas de planejamento e avaliação, por exemplo, entendendo o curso como integrado por completo.
\end{abstract}

Palavras-chave: Ensino Médio Integrado. Formação integrada. Licenciatura. Bacharelado. Concepção.

\section{THE INTEGRATED HIGH SCHOOL CONCEPT: A CONFRONTATION BETWEEN LICENSED AND BACHELOR'S TEACHERS}

\begin{abstract}
Integrated High School (EMI) to the technical course coexists with multiple interpretations among education professionals themselves. This article is the result of a research that aimed to investigate, through individual interviews with 16 effective teachers, the origin of this dissimilarity of the concept of teaching integration, in an attempt to find out whether the type of academic degree (licensure or bachelor's degree) of teachers interferes in the construction of this concept. The theoretical basis of this article was based on Ramos (2008), Ciavatta (2005) and Araújo and Frigotto (2015). As a result of the research, we identified that all 16 teachers interpret, by a functional bias, the concept of teaching integration in the same way, ie, implement professional education harmoniously to the propaedeutic disciplines, such as mathematics, Portuguese language, geography, biology and etc., so that knowledge for life and work are built indivisibly. On the other hand, in a holistic bias, only five teachers believe that integration should be fundamental not only in the moment of methodological choices for the exposure of content, but also in the stages of planning and evaluation, for example, understanding the course as fully integrated. Keywords: Integrated High School. Integrated course. Licensure. Bachelor's degree. Conception.
\end{abstract}

Recebido em: 10/10/2019

Aceito em: $17 / 4 / 2020$

\footnotetext{
1 Graduação em Letras, com Licenciatura Plena em Português/Inglês e respectivas Literaturas (Universidade Federal de Uberlândia, 2010). Pós-Graduação lato sensu em Direito Administrativo e Contratos (Universidade Cândido Mendes, 2017). Mestrado em Educação Profissional e Tecnológica (Instituto Federal do Triângulo Mineiro, 2019). Especialização em Educação Profissional e Tecnológica Inclusiva (Instituto Federal do Triângulo Mineiro, 2020). Secretária executiva no Instituto Federal do Triângulo Mineiro - Campus Uberlândia. http://lattes.cnpq.br/9322228644060538. https://orcid.org/0000-0002-8568-9550. sthefany@iftm.edu.br

2 Pós-Doutorado em Educação/Análise do Discurso (Universidade de São Paulo - USP). Doutorado em Estudos Linguísticos e Mestrado em Linguística (fomentado pela Capes) pelo Programa de Pós-Graduação em Estudos Linguísticos da Universidade Federal de Uberlândia (PPGEL/UFU). Especialização em Metodologia do Ensino-Aprendizagem em Língua Estrangeira - Língua Inglesa. Licenciatura Plena em Letras Português/Inglês e suas respectivas Literaturas. Bacharelado em Direito e Bacharelado em Teologia. Advogado inscrito na OAB-MG. Professor e pesquisador em regime de dedicação exclusiva do Instituto Federal de Educação, Ciência e Tecnologia do Triângulo Mineiro (IFTM). Líder do Grupo de Pesquisa em Discurso e Educação (GPDE/IFTM/CNPq). http://lattes.cnpq.br/1695154848013278. https://orcid. org/0000-0001-6766-4651.welissonmarques@iftm.edu.br
} 


\section{cater \\ \&Educaçẵo}

O Conceito de Ensino Médio Integrado:

Este artigo é fruto de uma pesquisa realizada durante o Mestrado Profissional em Educação Profissional e Tecnológica, vinculado ao Programa de Pós-Graduação em Educação Profissional e Tecnológica - ProfEPT, desenvolvido no Instituto Federal de Educação, Ciência e Tecnologia do Triângulo Mineiro (IFTM) Campus Avançado Uberaba Parque Tecnológico.

A proposta de realização desta pesquisa nasceu a partir de uma preocupação sobre qual seria o conceito de Ensino Médio Integrado (EMI) para o corpo docente do IFTM Campus Uberlândia, localizado na zona rural, a cerca de $25 \mathrm{~km}$ do centro da cidade de Uberlândia-MG, em uma região conhecida como Fazenda Sobradinho. A instituição foi fundada em 1957 e ofertava, no ano de 2019, quatro cursos de Ensino Médio integrados à Educação Profissional: Agropecuária, Manutenção e Suporte em Informática, Alimentos e Meio Ambiente.

O EMI surgiu a fim de articular dois polos, a educação para a vida e a educação para o mercado de trabalho, ou seja, o Ensino Médio regular, ofertado em escolas durante os comuns três anos de duração e constituído de disciplinas fragmentadas por áreas de conhecimento, e a Educação Profissional, oferecida por meio dos cursos técnicos profissionalizantes, destinados à capacitação de trabalhadores para o exercício de uma profissão. Desse modo, vislumbrar a Educação Profissional integrada requer pensar em estratégias, que, articuladas, possam promover a formação integral do sujeito, na perspectiva da emancipação, do pensamento crítico e da transformação social, rompendo as barreiras históricas dessa dualidade que se perpetua nos dias atuais (SILVA; HENRIQUE, 2017, s/p). Para tanto, independentemente de sua formação acadêmica, seja por meio da Licenciatura ou do Bacharelado, os docentes atuantes no EMI devem ser capazes de trabalhar de igual modo, todos dispostos a caminhar rumo a um horizonte emancipador e na ordem contra-hegemônica da sociedade do capital, formando um trabalhador pensante, crítico, autônomo e, principalmente, que tenha consciência das relações sociais das quais faz parte.

Este trabalho objetivou, portanto, analisar as concepções de integração de ensino de docentes atuantes em cursos técnicos integrados ao Ensino Médio do IFTM Campus Uberlândia. Com propósito analítico-interpretativista, esta pesquisa valeu-se de dados de natureza qualitativa, coletados via entrevistas individuais com 16 docentes de cargo efetivo, dos quais 8 são atuantes em disciplinas do Ensino Médio e 8 atuantes em disciplinas da Educação Profissional. Para tanto, solicitamos à Coordenação de Gestão de Pessoas (CGP) do Campus Uberlândia uma listagem com a relação de docentes efetivos e ativos no campus, ou seja, excluídos aqueles que prestassem serviços por tempo previamente delimitado ou que estivessem em licença ou afastados por algum motivo. Essa listagem nos foi repassada na data de 5 de novembro de 2018, na qual constavam 84 docentes. Entre eles 6 estavam em licença ou afastados e 1 encontrava-se em exercício em outro Instituto Federal, restando 77 docentes presentes na instituição àquela época. 
Com base, portanto, na listagem fornecida pela CGP, procedemos à seleção dos entrevistados a partir da formação acadêmica constante em seus currículos Lattes, verificados na mesma data de 5 de novembro de 2018. A análise do currículo Lattes ${ }^{3}$ possibilitou a identificação dos docentes quanto ao tipo de Graduação cursada por eles. Desse modo inicialmente foram selecionados para as entrevistas apenas aqueles docentes com um único tipo de Graduação, ou Licenciatura ou Bacharelado, excluídos aqueles com dupla formação, Licenciatura e Bacharelado. Em razão, porém, de trazer à pesquisa vozes de representantes docentes de todos os quatro cursos técnicos de Ensino Médio Integrado ofertados pelo Campus Uberlândia, julgamos pertinente inserir entre os 16 entrevistados alguns que, apesar de apresentarem dupla formação, pudessem carregar posicionamentos convenientes à hipótese desta pesquisa, de que haverá divergência de concepções quanto ao conceito de EMI entre docentes licenciados e docentes bacharéis.

As entrevistas foram realizadas no mês de novembro de 2018, gravadas por meio de gravador de voz portátil e transcritas de maneira mais fiel possível ao que foi enunciado pelos entrevistados, todavia em virtude da oralidade comum aos atos de fala, algumas expressões foram registradas conforme a ortografia da gramática normativa da Língua Portuguesa, a fim de mantermos a clareza, a padronização e a uniformidade dos textos transcritos. As entrevistas duraram em média 33 minutos, variando entre $16 \mathrm{e}$ 57 minutos de duração; nelas, todos os nomes pessoais foram substituídos por pseudônimos, e as informações que, de alguma forma, revelassem a identidade dos entrevistados foram reestruturadas no intuito de preservar o anonimato do sujeito. Entre as 16 entrevistas, 15 ocorreram de forma particular, isto é, somente com a presença do docente entrevistado e do pesquisador/entrevistador, e uma delas aconteceu, a pedido do próprio docente, em ambiente no qual se encontrava outro sujeito alheio à situação investigativa.

As entrevistas foram analisadas pela via do enfoque discursivo, buscando conferir vozes aos sujeitos envolvidos no artifício investigativo, a partir do que propõe a Análise do Discurso (AD). O processo de Análise do Discurso, adotado nesta pesquisa como parâmetro de análise dos dados coletados, pretende questionar os sentidos estabelecidos nas produções verbais dos entrevistados. A ideia principal da AD gira em torno de não existir sentido único para um enunciado. Existem múltiplas leituras para um texto, uma imagem ou um som, o que torna a língua opaca e heterogênea. A linguagem, portanto, é vista apenas como a materialidade do texto, o meio pelo qual o sujeito expõe os sentidos que pretende enunciar. Para Pêcheux (2016), a língua é a forma de materialização da fala, e o discurso, normalmente, produzido pela fala, terá sempre relação com o contexto histórico em que foi materializado. E, tendo por base o contexto histórico, é que o inconsciente/imaginário constrói a representação de ideias e posicionamentos do sujeito, estabelecendo o que se entende por ideologia.

A Plataforma Lattes foi escolhida por reunir a vida pregressa e atual dos estudantes e pesquisadores do país, sendo, hoje, adotada pela maioria das instituições de fomento a pesquisas e universidades e por apresentar, ainda, riqueza de informações e crescente confiabilidade entre os profissionais do Brasil. 
A fim de padronizarmos as terminologias utilizadas doravante neste artigo, entendemos como educação propedêutica o ensinamento preparatório ou introdutório de disciplinas básicas em um assunto, trata-se da etapa inicial em um processo de aprendizagem, por exemplo: Língua Portuguesa, Matemática, Física, Química, Biologia, História, etc. A educação propedêutica é comumente desenvolvida durante a Educação Básica, seja na pré-escola, no Ensino Fundamental ou no Ensino Médio. Neste estudo entendemos a educação propedêutica como objetivo do Ensino Médio, por ser uma etapa que visa a aprimorar as disciplinas-base adquiridas no Ensino Fundamental em direção à preparação cidadã do educando. Sendo assim, doravante trataremos de educação propedêutica como Ensino Médio (EM). Como Educação Profissional (EP) entendemos a aquisição teórica/prática de conhecimentos, habilidades e atitudes exigidas para o exercício de funções próprias de uma profissão, como: Avicultura, Lógica e Programação de Computadores, Instalações Agroindustriais, etc. A Educação Profissional, via de regra, envolve qualquer forma de ensino que vise à capacitação para o mercado de trabalho e é comumente desenvolvida por meio de cursos técnicos. Os cursos técnicos respondem por uma formação do aluno na esteira de uma educação comprometida com os interesses da classe trabalhadora. Assim sendo, doravante versaremos sobre Educação Profissional como sinônimo de curso técnico. Tomaremos ainda como sinônimos as expressões Ensino Médio Integrado, formação integrada e integração de ensino.

\section{RECORTES TEÓRICOS}

Neste tópico pretendemos apresentar o conceito de formação integrada segundo alguns autores da área (RAMOS, 2008; CIAVATTA, 2005; ARAÚJO; FRIGOTTO, 2015), a fim de conseguirmos, ao final, encadear as ideias e postularmos um conceito completo de integração, que nos permita identificar as concepções que estejam distantes de serem consideradas integradoras.

Para Marise Ramos (2008), em seu texto intitulado Concepção do Ensino Médio Integrado, que incorporou aspectos do debate realizado no seminário promovido pela Secretaria de Educação do Estado do Pará nos dias 8 e 9 de maio de 2008, são dispostos três sentidos para a conceituação do termo integração. Em um primeiro sentido, a autora atribui à integração um conceito filosófico, que expressa uma concepção de formação humana incorporando todas as dimensões da vida no processo formativo. Nesse primeiro sentido, a integração não se importa se a formação é geral ou profissionalizante e pode orientar tanto a Educação Básica quanto a Educação Superior. A integração possibilita a formação omnilateral ${ }^{4}$ dos sujeitos e demanda a integração das dimensões fundamentais da vida que estruturam a prática social: trabalho, ciência e cultura.

\footnotetext{
${ }^{4}$ Nos Manuscritos Econômico-Filosóficos ([1844] 2008), Karl Marx, em 1844, referia-se à formação omnilateral como a ruptura ampla e radical com o homem limitado/alienado da sociedade capitalista e a, consequente, construção de um homem omnilateral, constituído das mais variadas dimensões humanas, sejam elas: ética, afetiva, moral, estética, sensorial, intelectual, prática; no plano dos gostos, dos prazeres, das aptidões, das habilidades, dos valores, etc. A omnilateralidade, entretanto, só alcança a sua realização plena com a superação das determinações históricas da sociedade do capital, é uma práxis social coletiva e livre, que depende da universalização das relações não alienadas entre os indivíduos para a sua existência, tornando-se, portanto, uma formação praticamente inalcançável e utópica.
} 
O trabalho pode ser compreendido, basicamente, de forma ontológica ou de forma econômica. De forma ontológica, o trabalho é visto como realização humana inerente ao ser, ou seja, a ação do homem de interagir com a realidade para a satisfação de necessidades e produção de liberdade.

Nesse plano mais abstrato, parece desnecessário dizer que aqui não estou me referindo ao trabalho assalariado, fetichizado e estranhado (labour), mas ao trabalho como criador de valores de uso, o trabalho na sua dimensão concreta, como atividade vital (work), como "necessidade natural e eterna de efetivar o intercâmbio entre o homem e a natureza", nas conhecidas palavras de Marx (MARX, 1971, p. 50, 208 apud ANTUNES, 2003, p. 167).

Dessa forma, o trabalho não é emprego, não é a prática econômica que se configura na sociedade capitalista. Compreender o trabalho nessa perspectiva é entendê-lo como fonte originária e primária de realização do ser social, como fundamento ontológico básico da omnilateralidade humana. Por outro lado, o trabalho adquire também um sentido econômico, imprescindível para o funcionamento do sistema capitalista e regulado contratualmente na forma de emprego. Sob essa ótica, o trabalho se dá de maneira proeminente pela compra e venda da força de trabalho.

Se o trabalho, sob o sistema de metabolismo social do capital, assume uma forma necessariamente assalariada, abstrata, fetichizada e estranhada (dada a necessidade imperiosa de produzir valores de troca para a reprodução ampliada do capital), essa dimensão histórico-concreta do trabalho assalariado não pode, entretanto, ser eternizada e tomada a-historicamente (ANTUNES, 2003, p. 167, grifos do autor).

Nesse sentido econômico estruturam-se as práticas de profissionalização, de formação profissional como preparação para o exercício do trabalho. Carece de cuidados, no entanto, a profissionalização exacerbada, que transforma a escola em uma "indústria de aprendizagem", tornando-a um ambiente para formação exclusivamente tecnicista.

A ciência surge, nesse momento, como conhecimento produzido pela humanidade por meio do trabalho. O conhecimento, por sua vez, é legitimado socialmente porque, na condição de apropriação intelectual da realidade, explica e possibilita a intervenção sobre ela. Para Marise Ramos, o trabalho e a ciência formam uma unidade, uma vez que a ação humana é produtora de conhecimentos à medida que interage com a realidade e com a natureza.

A cultura, como outra dimensão fundamental da vida, integra os processos formativos trazendo os valores e normas que orientam e identificam um grupo social. A relação indissociável entre trabalho, ciência e cultura compreende o trabalho como princípio educativo, pois, como sujeito de nossa história e de nossa realidade, o ser humano é produtor de sua existência e, assim, apropria-se dela e pode transformá-la. Em um primeiro sentido, portanto, a integração é entendida como interdependência entre as dimensões fundamentais da vida, sejam elas o trabalho, a ciência e a cultura, contrapondo a ideia de profissionalização como simples formação para o mercado de trabalho; ela é, antes disso, a compreensão das dinâmicas socioprodutivas das sociedades modernas. 
O segundo sentido de integração proposto pela autora trata da indissociabilidade entre Educação Profissional e Educação Básica. Segundo ela, enquanto o Brasil se mantiver marcado por uma história escrita pela exploração dos trabalhadores, não é cabível uma formação para a vida se a profissionalização for deixada de lado. Para a classe trabalhadora brasileira e seus filhos existe a preocupação recorrente com a inserção na vida produtiva, quando os jovens tomam consciência dos limites que sua relação de classe impõe aos seus projetos de vida.

Não que se defenda a ideia de privilegiar a formação profissional em detrimento de uma formação geral, mas possibilitar aos sujeitos jovens e adultos se apropriarem de conhecimentos que estruturem a sua inserção na vida produtiva dignamente. É necessário desvincular as finalidades do Ensino Médio do mercado de trabalho e colocá-las sobre as necessidades do sujeito. Foi a partir do Decreto $n=5.154 / 2004$ que as necessidades dos trabalhadores foram identificadas. Tal dispositivo legal possibilitou aos sujeitos o desenvolvimento de uma educação integrada, garantindo o direito à Educação Básica e à possibilidade de uma formação para o exercício profissional. Nessa perspectiva do segundo sentido de integração, Ramos (2008) ressalta que mesmo os cursos meramente técnicos se sustentam com os fundamentos da Educação Básica, sendo, portanto, indissociáveis, condição necessária para se fazer a travessia para uma nova realidade.

O terceiro sentido propõe a integração de conhecimentos gerais e específicos como totalidade curricular. Como resquícios de um passado positivista e mecanicista das ciências, a maioria dos docentes costuma classificar as disciplinas como pertencentes ou a uma formação geral ou a uma formação específica. Segundo Ramos, há um consenso de que Língua Portuguesa, Matemática, Física, Química, Geografia, História, Artes, Educação Física, Línguas Estrangeiras sejam disciplinas propedêuticas, consideradas conhecimentos preliminares e básicos para uma formação para a vida. Por outro lado, Eletrônica, Elétrica, Análise Química, Contabilidade e outras seriam disciplinas de formação específica. Caso, contudo, os conhecimentos profissionalizantes não se vinculem aos conhecimentos propedêuticos, mantendo-se o ensinamento de forma isolada, eles não poderão ser utilizados em contexto diferente daquele em que foi ensinado.

Nesse sentido, o conceito de integração ressalta que a teoria desvinculada da prática torna-se abstrata e vazia e vice-versa. Um conhecimento de formação geral somente adquire significação quando reconhecido em sua realidade concreta e quando visualizado o seu potencial produtivo. A integração de conhecimentos no currículo é uma postura epistemológica que depende de cada um; cada professor deve tentar pensar em sua atuação vinculada aos ensinamentos dos seus pares, recorrendo a princípios e pressupostos da interdisciplinaridade e da visão totalizante da realidade.

Ciavatta, por sua vez, em artigo publicado no ano de 2005 na Revista Trabalho Necessário, esclarece que a finalidade primária da formação integrada é superar a dicotomia entre trabalho manual e trabalho intelectual. Historicamente, a educação brasileira discriminava uma minoria mais apta ao conhecimento, o que dividiu o ser humano entre aqueles responsáveis por pensar e aqueles responsáveis por executar. Por força do capitalismo e da supremacia burguesa, gênese da exclusão de grande parte da humanidade, a qual mantém-se até hoje relegada às atividades precarizadas e escoimadas de conhecimento, ao desemprego e à perda da própria identidade, nunca se deu importân- 
cia à incorporação da dimensão intelectual ao trabalho produtivo, na tentativa de formar trabalhadores capazes de atuar simultaneamente como operários e dirigentes. 0 conhecimento sempre foi uma reserva de poder das elites, nas quais se incluíam os filósofos, os sábios e os religiosos, e a instrução do povo era vista como obra beneficente e com conteúdos de formação basicamente técnicos, voltados para o trabalho produtivo.

Para Ciavatta (2005), falta ainda aos cidadãos brasileiros uma base cultural que permita tomar a integração como um valor, de modo a deixar de ver o trabalhador sempre como um subalterno, um sujeito condenado a uma secular dominação. Entender a integração como um valor é perceber que o trabalho manual demanda diversos outros domínios além de habilidades técnicas: são também necessárias competências relacionadas ao planejamento, à resolução de problemas, a cálculos matemáticos, à prevenção de riscos e outras dimensões cognitivas raramente destacadas para uma atividade operacional.

$\mathrm{Na}$ tentativa de concretizar uma formação integrada diante das possibilidades e realidades do sistema educacional brasileiro, Ciavatta elenca alguns pressupostos. O primeiro deles é a necessidade de um projeto social que envolvesse todas as instâncias responsáveis pela educação, sejam elas o governo federal, as Secretarias de Educação, a direção das escolas, os professores, etc. Nesse projeto haveria a manifestação de cada instância sobre as suas vontades políticas no que respeita à formação do aluno reduzida a simples preparação para o mercado de trabalho. Ainda que não se possa estar alheio às necessidades de sobrevivência, a educação de jovens e adultos não pode ser reduzida às vontades estritas do mercado de trabalho e ao tempo breve de produtividade do ciclo capitalista. $O$ segundo pressuposto pretende manter, na lei, a articulação entre o Ensino Médio de formação geral e a Educação Profissional, pois, como impedimento legal explícito seria mais custoso persistir no dualismo educacional. O terceiro pressuposto refere-se à elaboração coletiva de estratégias acadêmico-científicas de integração. Ciavatta declara ser preciso um momento de discussão dos processos de ensino-aprendizagem e também de elaboração prática do currículo integrador, que aproveite inclusive os ambientes de trabalho (visitas, estágios, etc.) para proporcionar a verdadeira articulação entre as disciplinas gerais e as específicas. O quarto pressuposto expõe a importância do processo de diálogo e de conscientização dos alunos e de suas famílias sobre as expectativas e possível realização de uma formação integrada. O sucesso da integração não se faz no isolamento institucional, mas com as variadas experiências compartilhadas com a escola, que deve considerar, nesta etapa, a visão que os alunos têm de si mesmos, as modalidades formativas oferecidas pela escola e as possibilidades de inserção laboral que o mundo externo lhes oferece. No quinto pressuposto reforça-se o exercício da formação integrada como experiência de democracia participativa, um movimento de ação coletiva e necessariamente social. Implica buscar colaboradores abertos à inovação que proporcionem ao aluno horizontes de captação do mundo além das rotinas escolares, com disciplinas e temas mais adequados à integração. $O$ trabalho deve tornar-se uma atividade libertadora, fundamental ao ser humano. O sexto e último pressuposto de uma efetiva formação integrada, segundo Ciavatta, é a garantia de investimentos na educação. Garantia de cumprimento, contudo, de todos os investimen- 
tos mínimos para a educação previstos na Constituição Federal, visto que não é possível a oferta pública e gratuita de serviços com qualidade sem as ferramentas essenciais que consolidem todos os já mencionados pressupostos.

Estes são pressupostos que supõem a valorização e a integração das diversas instâncias responsáveis pela educação no país como um todo e nos Estados. Supõem investimentos intelectuais, morais e financeiros, a administração inteligente de todo o processo e o envolvimento de alunos e professores em um horizonte comum. Deslindar a realidade do possível na formação integrada supõe o desafio da experimentação, da avaliação e da pesquisa de acompanhamento dos sucessos e dos limites de cada experiência (CIAVATTA, 2005, p. 17).

Por fim, trazemos o pensamento de Araújo e Frigotto (2015), que problematizam o projeto de ensino integrado e afirmam que o desenvolvimento de práticas pedagógicas integradoras requer, principalmente, soluções ético-políticas. Para eles, o ensino integrado é um direito de todos e promove o desenvolvimento de amplas faculdades físicas e intelectuais do aluno, comprometendo-se com a utopia de uma formação em sua totalidade. Contrariamente à fragmentação do saber, o ensino integrado vincula-se à ideia de desenvolver ações formativas integradoras que promovam a autonomia e a ampliação dos horizontes dos sujeitos das práticas pedagógicas, principalmente alunos e professores. O desenvolvimento de práticas pedagógicas integradoras, contudo, não depende somente de soluções didáticas, mas especialmente de soluções ético-políticas, ou seja, é necessária uma atitude humana transformadora por parte dos sujeitos do ensino e da aprendizagem.

Mas, por outro lado, não reduzimos a possibilidade do ensino integrado a um ato de vontade dos docentes e dos gestores educacionais; compreendemos que este depende, também, das condições concretas de sua realização, argumentamos que a promoção de práticas pedagógicas integradoras requer a constituição de um ambiente material que a favoreça e da busca permanente pelo elemento integrador, considerando as realidades específicas, a totalidade social e os sujeitos envolvidos (ARAÚJO; FRIGOTTO, 2015, p. 65).

Antes de tudo é imprescindível o compromisso do professor com as ideias de formação integrada e de transformação social, caso contrário os saberes, habilidades e atitudes em busca de um currículo integrado não passarão de capacidades específicas requeridas pelo mercado de trabalho. A formação integrada busca constituir o indivíduo em suas múltiplas capacidades: de trabalhar, de viver, de operar independentemente sobre a realidade, contribuindo para a construção de uma sociedade fraterna e justa.

Araújo e Frigotto (2015) utilizam a pesquisa realizada por Costa (2012) para apontar três ordens de problemas na materialização do ensino integrado: problemas de ordem conceitual, de operacionalização curricular e de organização dos sistemas de ensino. Salientamos, neste momento, que em nossa pesquisa visamos à investigação do problema de ordem conceitual, tomando como vertente a análise de diferenças conceituais em virtude do tipo de Graduação (Licenciatura ou Bacharelado) cursada pelo sujeito-professor.

O projeto de EMI, no entanto, tem sido entendido unicamente como uma estratégia de organização dos conteúdos escolares, mas não se pode resumi-lo a um projeto curricular de ensino. Trata-se, pois, de entender a ação pedagógica relacionada à to- 
talidade das ações humanas, na condição de ação ético-política de promoção da integração. Desse modo, o ensino integrado só cumpriria a sua finalidade se vinculado ao projeto político de construção de uma sociabilidade para além do capital. Ainda que existam diversas possibilidades de organizar as disciplinas/conteúdos para que o sujeito-aluno desenvolva autonomamente a capacidade de interpretar e agir sobre a realidade, o essencial é a formação ampla do sujeito-trabalhador e a sua articulação ao projeto ético-político de transformação social.

Não existe uma única técnica mais adequada para a instituição do ensino integrado, mas a escolha do arranjo a ser utilizado depende de várias circunstâncias: o perfil da turma, a experiência do docente, as condições estruturais do ambiente formador, etc. Partindo da premissa de que não há uma única forma correta, a reorganização curricular deve ser experimentada e avaliada para a realidade de cada ambiente educativo, mas deve sempre apresentar algum impacto sobre a produção/reprodução da sociedade.

Depois de entendida, portanto, a integração como ação ético-política e do compromisso docente com o esforço por uma formação, de fato, integrada, é fundamental a organização de um currículo integrador. Para isso Araújo e Frigotto (2015) elencam três princípios norteadores: a contextualização, a interdisciplinaridade e o compromisso com a transformação social.

A contextualização pressupõe a preocupação dos conteúdos formativos com a realidade social e com os projetos políticos dos trabalhadores e sua organização social, ou seja, a realidade de cada indivíduo é ponto de partida para a escolha dos conteúdos, a fim de trazer sentido para o processo de aprendizagem. A interdisciplinaridade é entendida como a exploração máxima das potencialidades de cada ciência. $\mathrm{O}$ maior obstáculo por um ensino interdisciplinar é a adoção de um objetivo específico por disciplina, ao passo que todas elas devem se sujeitar aos objetivos gerais da escola e à ação ético-política de transformar a realidade social. Por último, o compromisso com a transformação social é o reflexo do real propósito da formação integrada, a emancipação de uma histórica dualidade educacional que discriminava os trabalhadores braçais dos gerentes e trabalhadores intelectuais.

Nesse ponto, vale refletir sobre Freire (1967, p. 66), que argumenta não ser possível compreender a transição para formas mais evoluídas de sociedade sem uma visão do ontem. No caso brasileiro, a formação histórico-cultural insiste, direta ou indiretamente, em contribuir para a inexperiência democrática que permanece até hoje no país. O comportamento participante, que é a essência da própria democracia, foi negado durante a colonização do Brasil, à base de uma exploração econômica predatória e que impossibilitou as condições necessárias ao desenvolvimento de uma mentalidade flexível, crítica e participativa, típica do clima cultural democrático. Sem a oportunidade de uma vivência comunitária, sem a experiência da participação popular, nossa formação foi caracterizada pelo poder exacerbado e, consequentemente, pela submissão. Submissão que se desdobrava em ajustamento, acomodação e não integração.

A acomodação exige uma dose mínima de criticidade. A integração, pelo contrário, exige um máximo de razão e consciência. É o comportamento característico dos regimes flexivelmente democráticos. O problema do ajustamento e da acomodação se vincula ao do mutismo a que já nos referimos, como uma das consequên- 
cias imediatas de nossa inexperiência democrática. Na verdade, no ajustamento, o homem não dialoga. Não participa. Pelo contrário, se acomoda a determinações que se superpõem a ele. As disposições mentais que criamos nestas circunstâncias foram assim disposições mentais rigidamente autoritárias. Acríticas (FREIRE, 1967, p. 74).

A uma sociedade historicamente pressionada e sempre proibida de crescer, falar e interagir, pensar em contextualização, interdisciplinaridade e transformação social é uma experiência um tanto arrojada diante dos anos de estrangulamento à formação de uma mentalidade democrática e, por consequência, integradora.

Várias são, portanto, as estratégias de ensino para efetivar um ensino integrado, e nenhuma delas deve ser descartada, mas sim testadas e aplicadas na realidade educacional mais pertinente para cada momento. Cada estratégia, por conseguinte, pode trazer a sua contribuição para o desenvolvimento de práticas integradoras, sejam elas aulas expositivas, oficinas, passeios e visitas técnicas, jogos didáticos, aulas laboratoriais, etc. Sendo assim, práticas pedagógicas integradoras cumprem melhor ou pior o seu papel quanto mais estejam associadas à ideia de transformação da realidade social, desvinculada dos fins puramente capitalistas. A relação entre trabalho e ensino deve colaborar para a formação de homens omnilaterais, capacitados física e intelectualmente.

Nesse horizonte, a educação não se torna necessariamente profissionalizante, longe disso, mas confere à escola as bases necessárias que garantam a todos, indistintamente, uma formação capaz de desenvolver, de forma conjunta, a capacidade de trabaIhar manualmente e intelectualmente.

\section{RECORTES ANALÍTICOS}

Neste tópico buscamos responder à hipótese de nossa pesquisa: $\mathrm{O}$ tipo de formação em nível de Graduação (Licenciatura ou Bacharelado) do corpo docente entrevistado tem relação direta com a(s) concepção(ões) de integração de ensino do sujeito professor. Nessa etapa confrontamos as concepções sobre formação integrada entre os licenciados e os bacharéis e trazemos suas percepções quanto à necessidade de uma formação diferenciada para o estudante do Ensino Médio Integrado, e também para o professor atuante nesse contexto, por meio de três questionamentos.

Para essa questão inicial, descobrimos que todos os 16 docentes entrevistados compartilham a mesma concepção sobre integração de ensino em um viés funcional. Adotamos o termo funcional no sentido de que todos eles compreendem o EMI como uma forma de ensino que deva incorporar os conteúdos da base profissional aos conteúdos da base propedêutica própria do Ensino Médio regular e vice-versa. Dessa forma, a integração de conteúdos (ou integração de disciplinas) é vista como uma funcionalidade típica à formação integrada, ou seja, sua principal característica.

Porque muitas vezes a gente vê o integrado como matrícula, que faz um curso só, dois em um. Mas, eu entendo que o integrado, ele é muito além disso. Ele é o integrar conteúdos, integrar áreas do conhecimento. Então, eu acho que o integrado é você poder trabalhar Matemática, Química e disciplina de Solos, com Bovinocultura, isso é o integrar (Gabriel - bacharel). 
Julgamos oportuno, todavia, resgatar a concepção de Araújo e Frigotto (2015) ao afirmarem que o ensino integrado só cumpriria a sua finalidade se vinculado ao projeto político de construção de uma sociabilidade para além do capital. Assim sendo, ainda que existam conteúdos formativos para o mercado de trabalho, não se deve relegar a formação omnilateral do trabalhador e sua articulação a um projeto ético-político de transformação social.

Dessa forma, identificamos que alguns docentes demonstram se aprofundar em um conceito além do viés funcional que, reforçamos, considera a interdisciplinaridade entre conteúdos propedêuticos e profissionais. Entre os 16 entrevistados, 5 deles nos demonstraram um entendimento sobre integração de ensino que perpassa, dessa vez, por um viés holístico, 4 deles atuantes na EP e 1 atuante no EM. Vejamos o relato de João, atuante no Ensino Médio:

Então, essa é uma interação, de conteúdos, mas existe uma interação também que vai além dessa, que é a interação na maneira de conceber esse curso, você entendeu? Assim, já pensar um curso em que há integração por definição. Então, o que acontece hoje é que essa integração acaba dependendo muito do profissional, de iniciativas dos profissionais [...] A avaliação muitas vezes não é integrada [...] para haver uma integração real tudo isso teria que ser integrado, né? Teria que ter a comunicação entre os conteúdos, avaliações integradas... Não só as disciplinas, não só a cara, não só o nome do curso, entendeu? [...] Eu acho que a gente tem um curso integrado no nome, entendeu? Mas, que deixa a desejar em alguns aspectos ligados com a prática (João - licenciado e bacharel).

Assim como João, outros docentes reafirmaram essa concepção, tida por nós como holística, em virtude de acreditarem que a integração deva ser fundamental não somente no momento das escolhas metodológicas para a exposição dos conteúdos, mas também nas etapas de planejamento e avaliação, por exemplo. Utilizamos o termo holística em razão de os docentes acreditarem na integração de ensino em uma concepção integral, um curso integrado por completo, e não somente pela integração de conteúdos propedêuticos e profissionais, como relata Pedro:

Mas, efetivamente, eu não vejo isso sendo construído, a integração, realmente a integração. Eu não vejo isso sendo construído. Em nenhum curso que eu conheço dentro da instituição. Tem atividades. A gente tem atividades integradoras, é uma situação. Mas, um ensino realmente integrado eu desconheço (Pedro - bacharel).

Em síntese para esse primeiro questionamento, todos os 16 docentes entrevistados, licenciados e bacharéis, apresentaram a mesma concepção de formação integrada em um viés funcional, ou seja, acreditam que a integração de ensino seja efetivar uma comunicação entre as disciplinas propedêuticas do Ensino Médio e as disciplinas profissionais da Educação Profissional, em um caráter interdisciplinar. Em um viés holístico, apenas 5 docentes complementaram as suas concepções de formação integrada, de forma a entenderem que a integração de ensino vá além da interdisciplinaridade entre conteúdos e áreas do conhecimento e que compreenda todos os processos pedagógicos envolvidos dentro do curso de EMI, seja nas etapas de planejamento de aulas, nas avaliações ou em atividades e eventos extraclasse. 
Partimos agora para o segundo questionamento, que interpelou se os professores acreditam que o estudante do EMI tenha algum conhecimento/formação diferenciada ao formar-se nessa modalidade de ensino. Com essa pergunta buscávamos investigar entre os docentes se existe a preocupação com uma orientação crítica do estudante diante do mundo capitalista. Entre os 16 docentes entrevistados, apenas 2 deles mencionaram em suas respostas a importância de uma formação crítica desse estudante e futuro trabalhador perante o mundo capitalista. Um deles é o docente João, atuante no Ensino Médio.

[...] Mas, ao mesmo tempo, ele não pode deixar de receber informações fundamentais do ponto de vista da formação social, humana, filosófica, crítica. Então, eu acho que isso aí tem que estar... senão ele vai acabar se tornando apenas uma pessoa que vai repetir uma ação, né? Vai ser uma coisa mecânica (João - licenciado e bacharel).

Entre os 14 docentes restantes, destacamos 1 deles, que mencionou não saber se o conhecimento/formação é, de fato, diferenciado, mas apostou que o ensino é bom e de qualidade. Outro respondeu pontualmente não ser necessário nenhum conhecimento/formação diferenciada para o estudante do EMI, o docente Diego, atuante no Ensino Médio.

Ele não precisa ter conhecimento diferenciado nenhum. Ele só precisa estar atento que aqui ele faz dois cursos em um só. Ele faz o Ensino Médio e ele faz o Ensino Profissional. Ele não precisa ter um preparo. Ele precisa entender que essa integração... Química, Física, Biologia, Português, Matemática, Geografia... vai auxiliar ele nessa formação profissional, que é o intuito da instituição. [...] Ele precisa ter esse entendimento, não é conhecimento, é o entendimento como que funciona dois cursos em um só (Diego - licenciado).

No terceiro e último questionamento direcionamos a mesma pergunta anterior, porém aos docentes, e buscamos saber se eles acreditam ser necessário, ao docente do EMI incluindo eles próprios, um conhecimento/formação diferenciada para atuar nessa modalidade de ensino. Entre os 16 entrevistados, 12 responderam que é, sim, necessária uma formação diferenciada para o docente do EMI e, entre estes, 5 complementaram que tal formação diferenciada se dá de maneira aplicada, isto é, por meio de leituras, reuniões, debates ou treinamentos, haja vista que nenhum deles tem conhecimento sobre Graduações ou outra forma de educação formal que contemple a temática do Ensino Médio Integrado em seus currículos. Para eles, o conhecimento específico sobre EMI não é sinônimo de formação pedagógica por meio dos cursos de Licenciatura, por exemplo, pois nem mesmo os docentes licenciados tiveram acesso a discussões sobre integração de ensino durante o seu curso. ${ }^{5}$

\footnotetext{
Todos os 16 docentes entrevistados afirmaram não terem participado de nenhuma disciplina que discorresse sobre formação integrada, ou quiçá sobre Educação Profissional, durante a sua Graduação, até mesmo os licenciados. Entre eles, 15 disseram ter conhecido o Ensino Médio Integrado apenas quando ingressaram na rede federal, isto é, durante a preparação para o concurso público e posterior nomeação no cargo.
} 
Então, eu entendo [...] que nem sempre a formação pedagógica é o fiel da balança para a pessoa ser um bom professor. Porque, de repente, essa pessoa que não teve formação pedagógica nenhuma, mas durante a capacitação, a formação dele, ele teve professores que foram muito bons na área pedagógica, e ele se espelha nesse professor e traz essa experiência para cá e se dá bem ou, às vezes, ele interessa em se formar [...] Agora, a formação pedagógica, quero deixar bem claro para você aqui, ela é interessante, mas não é ela que vai fazer a pessoa ser um professor bom dentro da sala de aula (Diego - licenciado).

Além dos 12 docentes que acreditaram ser necessária uma formação específica para o EMI, 3 deles dispensaram um posicionamento parcial, e alguns disseram acreditar que, embora haja espaços para capacitações sobre integração de ensino na instituição, trabalhar de forma integrada ainda é uma escolha do docente, afinal, muitos deles, mesmo capacitados, não se dispõem a trabalhar em conjunto de forma interdisciplinar ou modificar suas práticas em sala de aula por desinteresse em planejar atividades diferentes das habituais. A última docente entrevistada, que destacamos nesse questionamento final, argumentou não acreditar ser primordial um conhecimento/formação diferenciada para os docentes do EMI, pois, para ela, os professores da instituição já são preocupados em se qualificar, tendo em vista que a maioria já apresenta o título de mestre ou doutor.

Não, não vejo que a gente tem algo de diferente. O nosso diferencial aqui no Instituto é que a maioria dos profissionais aqui, dos professores principalmente, os docentes, eles estão preocupados em se qualificar, né. Até porque o processo seletivo, ele exige de certa forma, né. [...] as pessoas estão preocupadas em se qualificar, eu não vejo que é só uma questão meramente por salário [...] eu acho que é uma questão, assim, de você se sentir bem, você poder dar uma contribuição melhor (Carolina - licenciada).

A opinião de Carolina corrabora os dados encontrados em nossa pesquisa, quando constatamos que a maioria absoluta dos docentes entrevistados teve seu primeiro contato com o EMI somente ao ingressar na instituição, mesmo já possuindo o título de mestre ou doutor. Nesta pesquisa, dos 16 docentes entrevistados, 11 deles já ingressaram na instituição apresentando ao menos o título de mestre, e ainda assim desconheciam o EMI, o que nos confirma a ideia de que as Pós-Graduações stricto sensu não são suficientes para capacitar os docentes quanto à formação integrada de ensino.

\section{CONCLUSÕES}

Relembramos, neste momento, que toda a análise realizada nesta investigação se apoiou nos discursos produzidos pelos docentes durante a ocasião da entrevista. Em síntese, não identificamos distinções entre docentes licenciados e docentes bacharéis, haja vista que todos os 16 entrevistados interpretam a concepção de formação integrada em um viés funcional, considerando a interdisciplinaridade entre conteúdos propedêuticos e profissionais uma característica peculiar a essa forma de ensino. Em um viés holístico, apenas 5 docentes compreendem a concepção de formação integrada como uma totalidade sistêmica, ou seja, acreditam que a integração de ensino demanda o pensamento integrado em todos os seus processos educativos, desde a etapa de plane- 
jamento do curso e das disciplinas, as quais deveriam ser realizadas em conjunto com todos os docentes, até mesmo a avaliação de todo o processo formativo pelos egressos do curso.

Quanto a uma formação diferenciada do estudante no EMI, todos os 16 entrevistados acreditam que a formação integrada é um ensino diferenciado em comparação ao tradicional Ensino Médio regular, pois nutre o sujeito com múltiplos conhecimentos interligados e contextualizados à sua realidade dentro e fora da escola, ainda que esteja sendo instaurada paulatinamente. Apenas 2 docentes, porém, mencionaram a sua preocupação com uma formação crítica do estudante perante o mercado de trabalho, de maneira que se formem cidadãos conscientes de sua história, e não apenas trabaIhadores braçais que atendam mecanicamente aos pedidos de seu empregador. Quanto a uma formação diferenciada do docente atuante no EMI, 12 entrevistados acreditam ser preciso uma preparação específica para o professor, ainda que nenhum deles tenha conhecimento de Graduações, Especializações ou Pós-Graduações relacionadas diretamente a essa temática ou que contemplem a formação integrada em seus currículos. Por esse motivo, 5 docentes disseram que tal preparação específica se dá por meio de aprendizagem aplicada, como eventos, reuniões e debates.

Percebemos, todavia, pelos três questionamentos realizados, que todos os 16 docentes entrevistados, em determinado momento de suas argumentações, expõem a nós alguma preocupação em formar o estudante quanto às habilidades e aos comportamentos requisitados pelo mercado de trabalho na área escolhida por ele, o que reflete a ideia de que o conceito de formação integrada não se vê distante da natureza capitalista, tornando-se uma concepção educacional sempre vinculada aos ditames econômicos e comerciais.

\section{REFERÊNCIAS}

ANTUNES, Ricardo. Os sentidos do trabalho: ensaio sobre a afirmação e a negação do trabalho. 6a reimpr. São Paulo: Boitempo Editorial, 2003.

ARAÚJO, Ronaldo Marcos de Lima; FRIGOTTO, Gaudêncio. Práticas pedagógicas e ensino integrado. Revista Educação em Questão, Natal-RN, v. 52, n. 38, p. 61-80, maio/ago. 2015.

BRASIL. Decreto no 5.154, de 23 de julho de 2004. Regulamenta o § 2o do art. 36 e os arts. 39 a 41 da Lei no 9.394, de 20 de dezembro de 1996, que estabelece as diretrizes e bases da educação nacional, e dá outras providências. Disponível em: http://www.planalto.gov.br/ccivil_03/_ato2004-2006/2004/decreto/ d5154.htm. Acesso em: 13 maio 2018.

CIAVATTA, Maria. A formação integrada: a escola e o trabalho como lugares de memória e de identidade. Revista Trabalho Necessário, ano 3, n. 3, 2005. Disponível em: http://www.uff.br/trabalhonecessario/ images/TN_03/TN3_CIAVATTA.pdf. Acesso em: 20 fev. 2018.

COSTA, Ana Maria Rayol da. Integração do Ensino Médio e Técnico: percepções de alunos do Instituto Federal de Educação, Ciência e Tecnologia do Pará - IFPA/Campus Castanhal. 2012. 118 f. Dissertação (Mestrado em Educação) - Programa de Pós-Graduação em Educação, Universidade Federal do Pará, 2012.

FREIRE, Paulo. Educação como prática de liberdade. Rio de Janeiro: Editora Paz e Terra, 1967.

MARX, Karl. Manuscritos econômico-filosóficos. Tradução Jesus Ranieri. São Paulo: Boitempo Editorial, [1844] 2008. 175 p.

PÊCHEUX, Michel. Semântica e discurso: uma crítica à afirmação do óbvio. Tradução Eni Puccinelli Orlandi et al. 5. ed. 1a reimpr. Campinas: Editora da Unicamp, 2016. 288 p.

RAMOS, Marise. Concepção de Ensino Médio Integrado. 2008. Disponível em: http://forumeja.org.br/go/ sites/forumeja.org.br.go/files/concepcao_do_ensino_medio_integrado5.pdf. Acesso em: 20 dez. 2017. 


\section{Revista \\ \&Educaçã̃o}

Sthéfany Araújo Melo - Welisson Marques

SILVA, Alyne Campelo da; HENRIQUE, Ana Lúcia Sarmento. Docentes não licenciados que atuam na educação profissional: relação entre formação, saberes e práticas. In: COLÓQUIO NACIONAL, 4; COLÓQUIO INTERNACIONAL, 1., 2017. Natal. Anais [...]. Natal, RN, 2017. (on-line). Disponível em: https://ead.ifrn. edu.br/coloquio/anais/2017/trabalhos/eixo3/E3A16.pdf. Acesso em: 2 ago. 2018. 